\title{
Removal of Chromium (VI) from Textile Waste Water by Using Activated Carbon Prepared from Neem Leaves and Garlic Husk
}

\author{
M. R. Priyadharshini ${ }^{1} \&$ K. Soundhirajan ${ }^{2}$ \\ ${ }^{I}$ PG Scholar, ${ }^{2}$ Assistant Professor, ${ }^{1,2}$ Department of Civil Engineering, Gnanamani College of Technology, \\ Namakkal, India. DOI: 10.46431/MEJAST.2021.4303
}

Crossref

Copyright: (02021 M.R.Priyadharshini \& K.Soundhirajan. This is an open access article distributed under the terms of the Creative Commons Attribution License, which permits unrestricted use, distribution, and reproduction in any medium, provided the original author and source are credited.

\begin{abstract}
This review of article is about the removal of Chromium (VI) from textile waste water by using activated carbon prepared from neem leaves and garlic husk. This article presents about adsorption, activated carbon and its process, characteristics of commercially activated carbon, methods to test characteristics of activated carbon, preparation of garlic husk and neem leaves and its adsorbent preparation. Also a detailed study report of physio chemical properties of activated garlic husk powder and neem powder, removal of heavy metal and its toxicity was discussed. The garlic husk powder and neem powder were activated using HCL in which the test results were comparatively same with commercially activated carbon. The particle size, yield, moisture content, ash content and pH of neem and garlic powder were found to be 875 micron and 850 micron, $60.540 \%$ and $58.60 \%, 6.25 \%$ and $7.50 \%, 3.10 \%$ and $4.10 \%, 6.80$ and 7.65 respectively. The main scope this project is to remove heavy metals from textile waste water in future with the help of prepared activated carbon using garlic husk and neem leaves. The present study is aimed at preparing the carbon from neem leaves and garlic husk by thermal activation procedure and will be tested for the removal of Chromium (VI) from aqueous solution. The results of the present study suggest that activated carbon from neem leaves and garlic husk can be used beneficially for chromium removal from aqueous solution.

Keywords: Chromium (VI), Neem leaves, Garlic husk, Activated carbon, Heavy metal, Toxicity.
\end{abstract}

\section{Introduction}

Textile is one of the main industries for the developing countries like India. These textile industries consumes large amount of water in its varied processing operations. Environmental problems of the textile industry are mainly causes by discharges of wastewater. Textile processing employs a variety of chemicals depending on the nature of the raw material and product. Some of these chemical are different dyes, detergents, acids, soda, enzyme and salts. Water containing these harmful constituents are toxic to many water organisms do imparts extremely disagreeable colour and odour. These effluents contain a large amount of various organic, inorganic dyes and various chemicals including traces of heavy metals ions.

These heavy metals produce undesirable effects and toxicity even if they are present in extremely minute quantities, on human and animal life. Heavy metals particularly, lead $(\mathrm{Pb})$, chromium $(\mathrm{Cr})$, Cadmium $(\mathrm{Cd})$, Copper $(\mathrm{Cu})$ and Nickel (Ni) are widely used for the production of color pigments of textile dyes [1]. These heavy metals which have transferred to the environment are highly toxic and can bio accumulate in the human body, aquatic life, and natural water-bodies and also possible trapped in the soil [2]. Exposure to metals can occur through a variety of routes. Metals may be inhaled as dust or fume; they may also be ingested involuntarily through food and drink. The amount that is actually absorbed from the digestive tract can vary widely, depending on the chemical form of the metal and the age and nutritional status of the individual. Once a metal is absorbed, it distributes in tissues and organs.

Water treatment is any process that improves the quality of water to make it appropriate for a specific end-use. The end use may be drinking, industrial water supply, irrigation, river flow maintenance, water recreation or many other uses, including being safely returned to the environment. Water treatment removes contaminants and undesirable components, or reduces their concentration so that the water becomes fit for its desired end-use. This treatment is 
crucial to human health and allows humans to benefit from both drinking and irrigation use. In wastewaters originating from dye industry there are amounts of dyes (very common methyl orange, methylene blue-MB) and heavy metals (cadmium, copper, nickel mainly from the organo-metallic dyes) [3-4]. They tend to adsorb in a competitive process and modify the substrate. Advanced removal is usually proposed via adsorption. Low-cost by-products from agricultural, household and industrial sectors have been recognized as a sustainable solution for wastewater treatment. They allow achieving the removal of pollutants from wastewater and at same time to contribute to the waste minimization, recovery and reuse.

A number of process methods have been developed for the removal of heavy metals from wastewater. These unit operations include Coagulation, Flocculation, Ion exchange, Precipitation, Complexation, Solvent extraction, Adsorption, Electro chemical operation and Flotation. The present study is aimed at preparing activated carbon from garlic husk and neem leaves and will be tested for its characteristics. Water treatment is the largest application of activated carbon. Most of the water treatment filters are made up of granular activated carbon. It is used for the removal of organic-chemical substances and colorants and reduces trace substances, such as chemicals. Activated carbon is used as a polishing step to remove dissolved organic and nonbiodegradable compounds, following physical and biological pre-treatment processes to remove solids and biological oxygen demand. Activated carbon removes the impurities from water primarily through surface adsorption. Usage of activated carbon for water purification purposes is also the most cost-efficient point-of use (POU) water purification devices. The neem leaves and garlic husk powder will be washed thoroughly with water and dried. The powder will be subjected to pyrolysis procedure at $450-600^{\circ} \mathrm{C}$ in the electrical furnace and then it will be activated under the temperature of 750 $800^{\circ} \mathrm{C}$ in the same furnace. The activated carbon will be grown well and the particle size 200-250 mesh will be considered for adsorption activities for the removal of Chromium (VI) from water [5]. Batch studies will be performed to understand the optimum time, optimum PH and optimum dosage required for preliminary examination. Carbon characteristics \& CSH will be found out to understand the potential of the carbon using ISI procedure 877-1976. Isotherm studies will be conducted to understand the capacity of carbon. A synthetically prepared nickel wastewater will be checked out for the removal of Chromium in batch reactor.

\section{Methodology}

Neem leaves garlic husk were collected from local area which were washed several times, dried at room temperature till it became crispy and grounded to fine powder, sieved to $125-250 \mu \mathrm{m}$, washed several times with distilled water. Then about $30 \mathrm{~g}$ GHP were boiled in a $250 \mathrm{ml}$ beaker adding $5 \mathrm{ml},(2 \mathrm{~N}) \mathrm{HCl}$ to activate the adsorbents and to remove soluble impurities. The powder form of neem leaves and garlic husk were filtered and boiled 2-3 times with distilled water again and dried at room temperature for $48 \mathrm{~h}$. It was kept in the oven at about $40-50^{\circ} \mathrm{C}$ for $5-6 \mathrm{~h}$, to remove the moisture completely and dry activated carbon were kept in an air tight vessel.

The waste water samples for this experiment were collected from a textile unit in Tiruchengode, Namakkal district. The fresh wastewater samples were collected from the influent collection of the wastewater treatment plant using plastic bottles. The $\mathrm{pH}$ and temperature of the wastewater samples were recorded using $\mathrm{pH}$ meter. Before collecting the wastewater sample, the plastic bottles were washed thoroughly using distilled water. Standard solutions of $\mathrm{Cr}$ 
(0 to $2 \mathrm{ppm}$ ) were prepared from the stock solutions (1000 ppm). These standard solutions were used in the Atomic Absorption Spectrometry (AAS) analysis. Before the initial concentration of heavy metals in wastewater samples was done, the samples were filtered using Whatman filter paper with diameter size of $47 \mathrm{~mm}$ mechanically. The filtered sample was poured into plastic test-tubes for analysis using AAS.

\subsection{Adsorption}

Adsorption is the adhesion of atoms, ions or molecules from a gas, liquid or dissolved solid to a surface. This process creates a film of the adsorbate on the surface of the adsorbent. This process differs from absorption, in which a fluid is dissolved by or permeates a liquid or solid (the absorbent), respectively. Adsorption is a surface phenomenon, while absorption involves whole volume of material, though adsorption often precedes absorption.

\subsection{Activated Carbon}

Activated carbon, also called activated charcoal, is a form of carbon processed to have small, low - volume pores that increase the surface area available for adsorption or chemical reactions. It is one of the most effective media for removing a wide Range of contaminants from industrial and municipal waste waters, landfill leachate and contaminated groundwater. Different contaminants may be present in the same discharge and carbon may be better utilized to remove specific contaminants as part of a multistage approach.

\subsection{Characteristics of Commercial Activated Carbons}

The activated carbon is produced from various raw materials and therefore, it presents different properties. Apart from the raw material, the specific properties of the coal also depend on the particular activation process employed, which may be conducted by physical processes, by contact with a high temperature steam flow $\left(800-1000^{\circ} \mathrm{C}\right)$ or, by chemical with use of acids. The bulk density may be used in order to identify several activated carbon classes. The macro porous carbon has a bulk density $>1 \mathrm{~cm} 3 / \mathrm{g}$ (pore space volume for gram of carbon). The mesoporous carbon has a bulk density in the range $0.85-1.0 \mathrm{~cm} 3 / \mathrm{g}$. Instead, the microporous carbon presents a value $<0.85 \mathrm{~cm} 3 / \mathrm{g}$. Generally, macro porous or mesoporous carbons are used for the removal of large molecules while, microporous, are more suitable for the removal of small molecules. The content of ash, another characteristics parameter, depends on the raw material used. Generally, its value increases with the number of regeneration cycles, with a percentage increase of $0.5-1.0 \%$ for each cycle. This involves a consequent limitation of the number of possible regenerations. For activated carbons, the content of ash is $<15 \%$. The Iodine number is an index of the ability of the sorbent to adsorb small molecules, expressed in $\mathrm{mg}$ of iodine adsorbed per gram of carbon. For activated carbons, the Iodine number varies in the range $500-1200 \mathrm{mg} / \mathrm{g}$. Finally, another important parameter is the specific surface area expressed in $\mathrm{m} 2 / \mathrm{g}$. Generally, adsorption capacitates increase with the growth of this parameter. In the case of activated carbons, the specific surface area varies in the range $500-1500 \mathrm{~m} 2 / \mathrm{g}$.

\section{Methods to Test Characteristics of Activated Carbon}

\subsection{Bulk Density}

The test is carried out in a graduated cylinder, fixed in a vertical tapping device, frequency $250 \pm 15$ taps $/ \mathrm{min}$., amplitude $3 \mathrm{~mm}$. Place approximately $200 \mathrm{ml}$ of activated carbon in the cylinder, avoiding entraining air. Flatten 
the top layer by tapping the side of the cylinder, Fix the cylinder onto the machine and cycle 1250 times, Read the volume $(\mathrm{V})$ and repeat the procedure until the difference between two observations is less than $2 \mathrm{ml}$.

\subsection{Particle Size of Granular Carbon}

Many sieving methods, differing only in duration and technique of sieving (mechanical or manual), are used.

\subsection{Moisture Content}

Put the sample into a pre-dried tared weighing bottle or crucible with lid, close and weigh at once to the nearest 0.5 $\mathrm{mg}$. Remove the lid and place the container and lid in a preheated forced circulation oven $\left(\right.$ at $\left.150^{\circ} \mathrm{C}\right)$, Close the oven and dry to constant weight (3h is normally sufficient) Open the oven and close the container quickly. Cool in a desiccator to ambient temperature and weigh.

\subsection{Ash Content}

Ignite the crucible in the muffle furnace at $650 \pm 25^{\circ} \mathrm{c}$ for $1 \mathrm{~h}$. Place the crucible in the desiccator. Cool to room temperature and weigh to the nearest $01 \mathrm{mg}$, Weigh out to the nearest $0.1 \mathrm{mg}$ sufficient dried activated carbon, so that the estimated amount of ash will be $0, \mathrm{Ig}$, into the ignited crucible. Place the crucible in the furnace at $650 \pm$ $25^{\circ} \mathrm{c}$. Ashing will take from 3 to $16 \mathrm{~h}$, depending on the type of activated carbon and its particle size. Ashing can be considered complete when constant weight is achieved. Place the crucible in the desiccator and allow cooling to room temperature.

\subsection{PH Value}

Weigh out $40 \mathrm{~g}$ of carbon into a $250 \mathrm{ml}$ beaker, add $100 \mathrm{ml}$ of distilled, $\mathrm{C}_{2}$ free (boiled out) water cover with a watch glass and boil on the hot-plate for 5 minutes. O Insert the thermometer and set aside for a few moments to allow the bulk of the activated carbon particles to settle. Pour off the supernatant liquid as soon as possible and before it cools to $60^{\circ} \mathrm{C} \mathrm{Cool} \mathrm{the} \mathrm{decanted} \mathrm{portion} \mathrm{to} \mathrm{room} \mathrm{temperature} \mathrm{and} \mathrm{measure} \mathrm{the} \mathrm{pH}$ to one decimal place.

\subsection{Properties of Activated Carbon from Neem}

\begin{tabular}{|c|lc|}
\hline S. No. & PARAMETERS & SAMPLE \\
\hline 1 & Moisture (\%) & 6.25 \\
2 & Dry matter (\%) & 90.50 \\
3 & Ash content (\%) & 3.10 \\
4 & Bulk Density $\left(\mathrm{g} / \mathrm{cm}^{3}\right)$ & 0.85 \\
5 & Yield (\%) & 60.50 \\
6 & Particle size (micron) & 875 \\
7 & pH measurement & 6.80 \\
\hline
\end{tabular}


3.7. Properties of Activated Carbon from Garlic Husk

\begin{tabular}{|c|lc|}
\hline S. No. & Parameters & Sample \\
\hline 1 & Moisture (\%) & 7.50 \\
2 & Dry matter (\%) & 92.53 \\
3 & Ash content (\%) & 4.10 \\
4 & Bulk Density $\left(\mathrm{g} / \mathrm{cm}^{3}\right)$ & 0.75 \\
5 & Yield (\%) & 58.60 \\
6 & Particle size (micron) & 850 \\
7 & pH measurement & 7.65 \\
\hline
\end{tabular}

\subsection{Properties of Activated Carbon from Local Store}

\begin{tabular}{|c|lc|}
\hline S. No. & Parameters & Sample \\
\hline 1 & Moisture (\%) & 5.20 \\
2 & Dry matter (\%) & 75.80 \\
3 & Ash content (\%) & 3.75 \\
4 & Bulk Density $\left(\mathrm{g} / \mathrm{cm}^{3}\right)$ & 0.95 \\
5 & Yield (\%) & 62.15 \\
6 & Particle size (micron) & 825 \\
7 & pH measurement & 7.40 \\
\hline
\end{tabular}

\subsection{Graphical Representation}

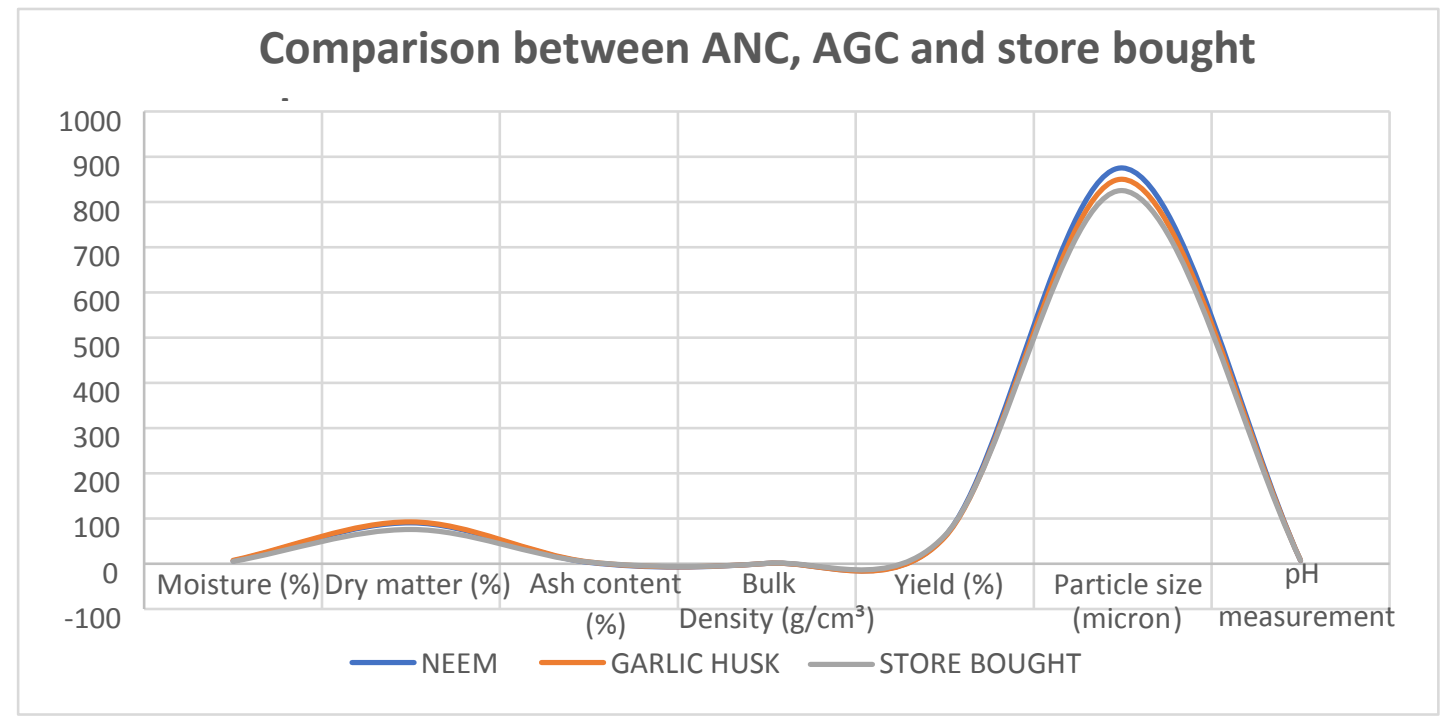




\section{Heavy Metal Pollution}

Textile effluents contain high concentration dyes and chemicals and contain traces of heavy metal capable of causing several health-related issues and contain microorganism. Occasionally, heavy metals can occur naturally in the fibre structure. Alternatively, it can be reintroduced into the textile fabric during manufacturing processes those comes from dyeing and finishing processes due to the use of high fastness and dye resistance properties.

The heavy metal also occurs from four primary dyes: metal complex acid dyes, chrome acid dyes, reactive metal-containing dyes and direct metal-containing dyes. Heavy metals can also come from fiber's chemical treatment to improve resistance to light and wet factors and fabric bleaching processes where metals are used as catalysts for oxidants.

Heavy metal pollution through industrial waste is a serious environmental issue throughout the world. Heavy metals are a group of metals and metalloids with an atomic density of more than $4000 \mathrm{~kg} . \mathrm{m}^{-3}$, atomic weights between 63.5 and 200.6 and gravity >5.0 Lead, cadmium, copper, arsenic, nickel, chromium, zinc and mercury have been recognized as hazardous heavy metals, because of their high solubility in the aquatic environments. Besides, heavy metals can be absorbed by living organisms, which are toxic even at low concentration.

These metals are harder to clean due to its complex chemical form and non-biodegradability. Moreover, the above-mentioned heavy metals are stable, toxic and carcinogenic, accumulation in living organisms cause a severe health problem. Our natural soil and natural water resources are noxiously polluted by these heavy metal discharge which then adsorbed by plants through contaminated soil and then entering other living organisms through the food chain, affecting the environmental activities.

Apart from the textile industry, other heavy metal toxicities releasing industries are mining, electroplating, metal processing, battery manufacturing, tanneries, petroleum refining, paint manufacture, pesticides, pigment manufacture, printing and photographic industries. World health organisation (WHO) and Environmental protection agency (EPA) set permissible discharge standard limit for heavy metal to control the environmental pollution.

When people continuously exposed to this toxic heavy metal causes various severe health-related deceases such as cancers and cardiovascular, pulmonary, immunological, neurological and endocrine disorders. Heavy metal removal from inorganic effluent can be achieved by conventional treatment processes which include chemical precipitation, electrochemical treatment, adsorption, coagulation-flocculation, membrane separation, ion exchange, reverse osmosis and biological treatment and so on.

These methods are efficient in heavy metal removal even though they have some limitations such as high energy consumption, incomplete removal, secondary pollutants, high cost, high-energy requirements, and toxic sludge production. According to the previous literature review, the adsorption process is one of the low expenses among these remediation methods, a highly efficient advantageous method for removing heavy metals.

From that point of view, this review focuses on the adsorption of heavy metals from textile wastewater; specifically, metal ions such as chromium $(\mathrm{Cr})$, cadmium $(\mathrm{Cd})$, lead $(\mathrm{Pb})$ and zinc $(\mathrm{Zn})$. 


\subsection{Heavy Metals and Their Toxicity}

\begin{tabular}{|c|c|c|}
\hline S. No. & Heavy Metal & Toxicity \\
\hline 1 & Cadmium $(\mathrm{Cd})$ & Kidney damage, renal disorder, human carcinogen. \\
\hline 2 & Chromium (Cr) & Headache, diarrhoea, nausea, vomiting, carcinogenic. \\
\hline 3 & Copper $(\mathrm{Cu})$ & Liver damage, Wilson disease, insomnia. \\
\hline 4 & Nickel (Ni) & Dermatitis, nausea, chronic asthma, coughing, human carcinogen. \\
\hline 5 & Zinc $(\mathrm{Zn})$ & Depression, lethargy, neurological signs and increased thirst. \\
\hline 6 & Lead $(\mathrm{Pb})$ & $\begin{array}{l}\text { Damage the fetal brain, diseases of kidney, circulatory system and } \\
\text { nervous system. }\end{array}$ \\
\hline 7 & Mercury (Hg) & $\begin{array}{l}\text { Rheumatoid arthritis and kidney disease, circulatory system and } \\
\text { nervous system. }\end{array}$ \\
\hline
\end{tabular}

\subsection{Chromium}

Chromium $(\mathrm{Cr})$ is a harmful heavy metal and oxidation states ranging from +2 to +6 . Among these ranges, the trivalent and hexavalent states are considered more toxic, non-biodegradable, carcinogenic, teratogenic and mutagenic because of its oxidizing properties. $\mathrm{Cr}$ (III) is one of the essential elements for living being's health at a low level with a nontoxic concentration of $0.20 \mathrm{mg} /$ day whereas $\mathrm{Cr}$ (VI) is a strong carcinogenic and pestilential to humans and animals. Furthermore, chromium is categorized as group 1 carcinogenic by the International Agency for Research on Cancer (IARC) for animals and humans. The toxicity of hexavalent chromium Cr (VI) is normally 1000 times higher than that of $\mathrm{Cr}$ (III) trivalent chromium. Accordingly, the World Health Organization (WHO) recommends that the chromium content in drinking water must be $<50 \mathrm{ppb}$ or $0.05 \mathrm{mg} \mathrm{L}^{-1}$ and European Union require that the discharge of $\mathrm{Cr}(\mathrm{VI})$ to surface water should be below $50 \mu \mathrm{g} \mathrm{L}^{-1}$. Chromium (VI) is dangerous to health when the limit $\left(0.05 \mathrm{mg} \mathrm{L}^{-1}\right)$ exceeds in potable water. Various methods available to treat this metal ion, including ion exchange, photo-catalysis, electrochemical flocculation, membrane separation, chemical precipitation, ion exchange and adsorption have been used to decontaminate chromium ions from aqueous solution and reach the WHO permissible limit. Among these methods, adsorption is a highly efficient method due to its simple operation, high efficiency, and economic feasibility. Adsorbents, such as activated carbon, ion-exchange resins, inorganic nanomaterials, and natural waste material were reported to remove chromium ions in wastewater. Because of the limitations of these materials such as high cost, slow and less amount of adsorption efficiency enhanced the demand for low-cost adsorbent with high removal efficiency.

\subsection{Variation of Dosages and Contact Time}

$30 \mathrm{ml}$ of sample solution with chromium concentration are prepared. Then a constant $\mathrm{pH}$ of 5.4, the various dosages of $1 \mathrm{~g}, 2 \mathrm{~g}, 3 \mathrm{~g}$ adsorbents are stirred in the sample by using magnetic stirrer. The influence of contact time 
on adsorption of heavy metal on the adsorbents is examined for $5 \mathrm{hrs,} 24 \mathrm{hrs}$. Langmuir isotherm study was carried out with different initial concentration of $\mathrm{Cr}$ (VI) from 5 to $40 \mathrm{mg} / \mathrm{L}$, while maintaining the adsorbent dose at 50 $\mathrm{mg} / 50 \mathrm{ml}$. Desorption studies was carried out to confirm the adsorption mechanism proposed above and to recover the metals from the adsorbent using 0.025 to $0.350 \mathrm{M}$ hydrochloric acid.

\section{Results and Discussion}

\subsection{Effect of Agitation Time on Chromium (VI) Adsorption}

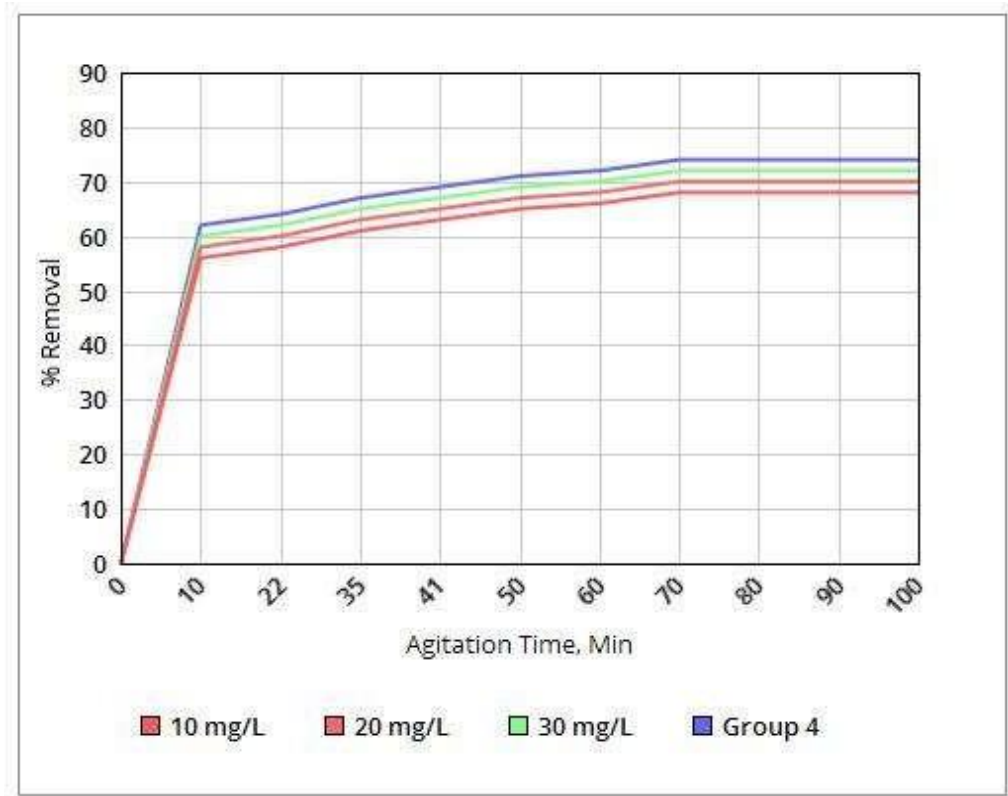

The effect of agitation time on the percent removal of $\mathrm{Cr}(\mathrm{VI})$ by activated carbon is shown in Figure1. The percent removal increases with increase in agitation time and attains equilibrium within $65 \mathrm{mts}$ for all the concentrations studied (10 to $40 \mathrm{mg} / \mathrm{L}$ ). The curves were single, smooth and continuous till the saturation of $\mathrm{Cr}$ (VI) on activated carbon surface.

\subsection{Effect of Adsorbent Dosage on Cr (VI) Adsorption}

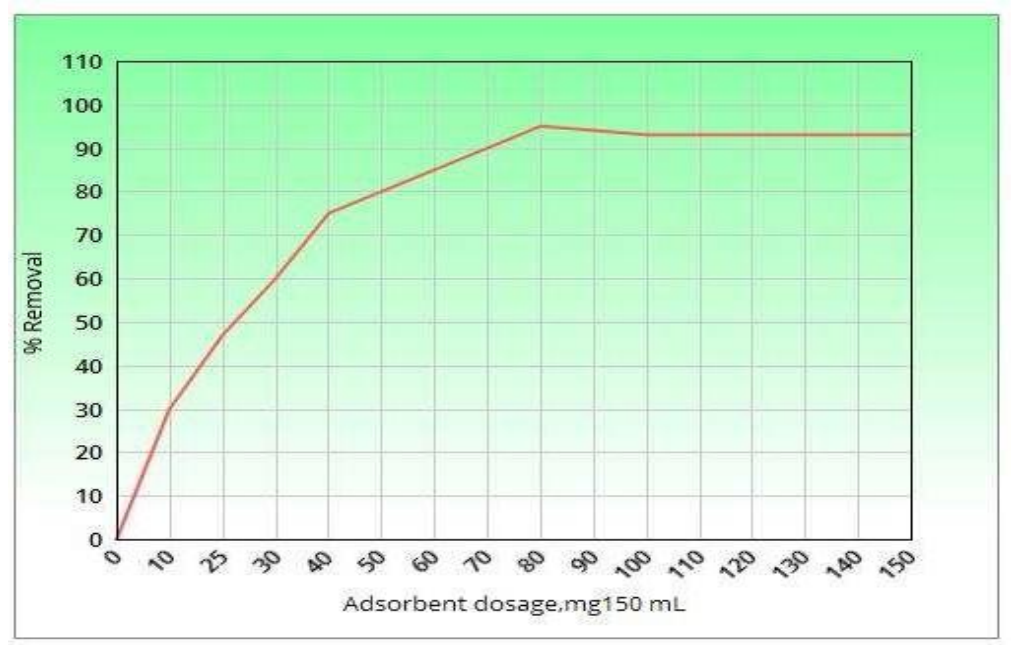

The effect of carbon dosage on percent removal of $\mathrm{Cr}$ (VI) is shown in Figure 2. When the carbon dosage increases, the percent removal also increases. It was found that for the removal of $\mathrm{Cr}(\mathrm{VI})$ of $30 \mathrm{mg} / \mathrm{L}$, the 
maximum adsorbent dosage of $70 \mathrm{mg} / 40 \mathrm{~mL}$ was required. Increasing adsorbent dosage increases the removal because of availability of more surface area and functional group.

\subsection{Effect of pH on Chromium (VI) Adsorption}

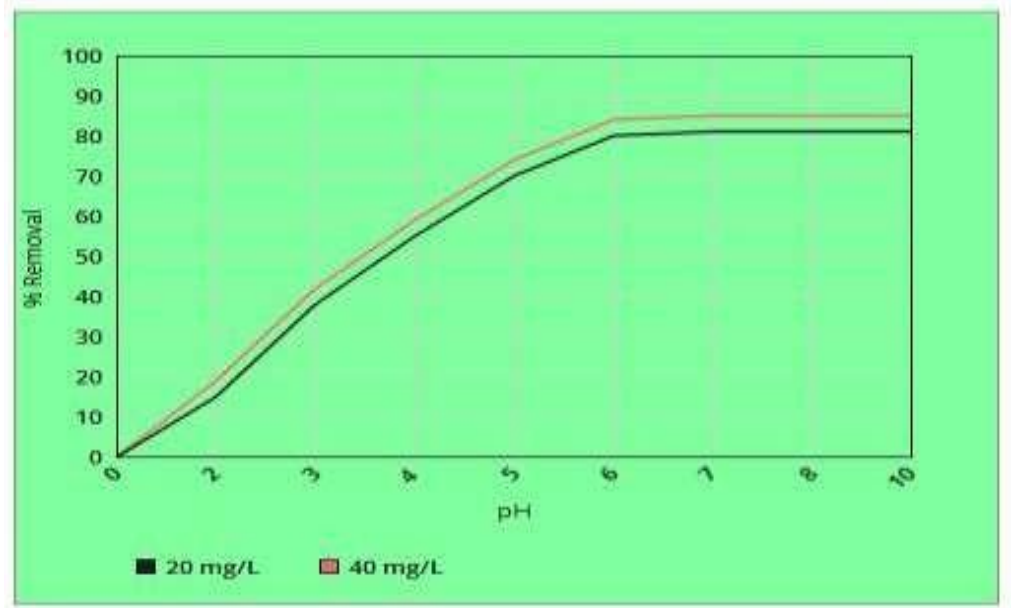

The effect of $\mathrm{pH}$ from 2.0 to 10.0 was studied to remove $\mathrm{Cr}$ (VI) ions from the aqueous solution with adsorbent (Figure). The precipitation was observed from the results at $\mathrm{pH} 8.0$ onwards and the intensity of precipitation increases with the increase in $\mathrm{pH}$ from 8.0 to10.0. Similar observations were reported for coir pith carbon 14 . The removal of metal ions increases with increase in $\mathrm{pH}$ from 8.0 to 10.0 even without adsorbent, this is may be due to the formation of metal hydroxide precipitation.

\section{Conclusion}

In the present project study, a waste organic source material such as neem leaves and garlic husk were used and subjected to carbon preparation. The current investigation shows that this activated carbon is very effective adsorbent in removal of $\mathrm{Cr}$ (VI) ions from aqueous solution. The carbon was able to remove $\mathrm{Cr}$ (VI) by adsorption mechanism. Increase in adsorbent dosage and agitation time increases $\mathrm{Cr}$ (VI) ion removal at the optimum $\mathrm{pH}$ of $5 \pm 0.2$. The adsorption followed both Langmuir and Freund lich isotherm models.

The desorption studies reveal that recovery of Cr (VI) ions from adsorbent is possible. Thus, it can be concluded that activated neem and garlic husk carbon can effectively be used for the removal of $\mathrm{Cr}$ (VI) from aqueous solution.

\section{Declarations}

\section{Source of Funding}

This research did not receive any grant from funding agencies in the public, commercial, or not-for-profit sectors.

\section{Competing Interests Statement}

The authors declare no competing financial, professional and personal interests.

\section{Ethical Approval}

Not Applicable. 
Consent for publication

Authors declare that they consented for the publication of this research work.

Availability of data and material

Authors are willing to share data and material according to the relevant needs.

\section{References}

[1] Alagesan Kannan (2014) Removal of cadmium from aqueous solution using carbon derived from Palmyra palm fruit seed, International Journal of Hazardous Material, Vol. 2, No.1, pp.1-6.

[2] Bernard (2003) Heavy Metals Removal from Industrial Wastewater by Activated Carbon prepared from Coconut Shell, Research Journal of Chemical Sciences, Vol.3, No.8, pp.3-9.

[3] Huang (1983), Activated Carbon Process for the Treatment of Cadmium (II)-Containing Wastewaters, Industrial Environmental Research Laboratory, Vol. 600, No. 2, pp. 8 3-061.

[4] Chin-pao Haung (1978) Removal of Cadmium (II) by Activated Carbon, Journal of the Environmental Engineering Division, Vol.104, No.5, pp.863-878.

[5] Cristina Quintelas (2009) Removal of Cd(II), Cr(VI), Fe(III) and Ni(II) from aqueous solutions by an E. coli biofilm supported on kaolin, Chemical Engineering Journal, Vol.149, pp.319-324. 